\title{
U-shaped backward masking functions with nonmetacontrast paradigms*
}

\author{
DEAN G. PURCELL $\div$ \\ Graduate Faculty. New School for Social Research. New York, N.Y. 10011 \\ and \\ ALAN L. STEWART \\ York University, Downsview, Ontario, Canada
}

As the interval from the onset of a target letter to the onset of a masking stimulus is increased. target recognition first becomes worse and then improves under some conditions. Previously, these U-shaped functions have been documented only when metacontrast masking paradigms have been used. In the present studies, U-shaped functions were found with nonmetacontrast paradigms. Using a pattern mask, U-shaped functions were found when the target energy was greater than the mask energy. Moreover, a set of parameters was found that produced U-shaped functions when no contours were present within the masking field.

Two visual stimuli, presented closely in time to the same or adjacent retinal area, may interact so that an $\mathrm{O}$ is unable to report one stimulus or the other. When the report of the first stimulus is interfered with by the second, the effect is generally called visual backward masking. The first stimulus is referred to as the target and the second as the mask.

The temporal course of backward masking has been investigated by manipulating the interval between the target onset and the mask onset. In the following discussion, this interval will be referred to as $-\Delta t$. In general, two types of visual backward masking functions are reported when $-\Delta t$ is varied systematically. Under some conditions, visual backward masking decreases as $-\Delta t$ increases. Under other conditions, backward masking is reported to be minimal at short $-\Delta \mathrm{t}$ values, but, as $-\Delta t$ becomes larger, masking first increases and then returns to some minimal level (see Raab, 1963; Kahneman, 1968; Weisstein, 1968). This effect is referred to as a U-shaped visual backward masking function.

Backward masking paradigms where the target and mask contours fall on adjacent retinal areas and do not overlap spatially are classified as metacontrast paradigms. Recent reviews of the visual masking literature (Kahneman, 1968: Weisstein, 1968) report that U-shaped masking functions are obtained when the target and mask are approximately equal in energy,

* This research was supported by grants from the National Research Council of Canada (APA 191 to M. C. Smith), and Defence Research Board of Canada ( $9401-38$ to M. C. Smith). Preparation of the manuscript was also supported under a National Research Council of Canada Grant (APA 300 to L. H. Theodor).

$\div$ Department of Psychology, Graduate Faculty, New School for Social Research. 66 West 12 th Street. New York, X. Y', 10011. under metacontrast conditions. They do not report any $U$-shaped functions under nonmeracontrast conditions. Unless U-shaped masking functions can be demonstrated under nonmetacontrast conditions, the available data would suggest that these functions are unique to metacontrast paradigms.

Backward masking does not conform to the metacontrast paradigm when flashes of light or overlapping patterns are used as masks. In the first case, there is no contoured figure in the masking flash, and in the second the masking contours spatially overlap those of the target. The three experiments reported in this paper were designed to investigate possible U-shaped backward masking functions using nonmetacontrast paradigms.

\section{EXPERIMENT 1}

In Experiment 1 the target and the mask durations were set at $20 \mathrm{msec}$, and the white portions of the target and mask fields reflected $20 \mathrm{fL}$. All other fields were dark for each of the three experiments. The target presentation consisted of one or the other of the letters " $A$ " or " $T$ " as black letters on a white background. They subtended approximately $24 \times 28.8 \mathrm{~min}$ of arc, with a strip width of $4.8 \mathrm{~min}$. In all three experiments the target was presented at the center of fixation. The fixation point was defined by a diamond pattern of four dim, red dots, each dot located $100 \mathrm{~min}$ from the field center. The mask consisted of overlapping columns and rows of the letters " $N$ " and " $O$," and subtended $287 \times 143 \mathrm{~min}$ of arc. The individual letters comprising the mask were of approximately the same size as the target letters. A Scientific Prototype tachistoscope (GB) was used to present the stimuli.

Four highly trained Os participated in the experiments. Os were dark adapted for
10 min prior to each experimental session. In all three experiments the observation was monoptic, right eye. A trial consisted of the presentation of one of the target letters and the mask at an appropriate $-\Delta t$ value. The target letter presented, "A" or "I," was varied randomly from trial to trial, with the stipulation that both letters be presented 25 times per 50 trials. Os had to respond " $A$ " or " $T$ " on each trial. The intertrial interval was $10 \mathrm{sec}$. The values of $-\Delta t$ investigated were $0,10,20,40$, and 80 msec. $A-\Delta t$ of 0 corresponded to simultaneous presentation of the target and the mask fields. Likewise, a $-\Delta t$ of $10 \mathrm{msec}$ corresponded to an overlap of the last $10 \mathrm{msec}$ of the target field presentation and the first $10 \mathrm{msec}$ of the mask field presentation. Each of the five conditions of $-\Delta t$ were presented in blocks of 10 trials, with blocks randomized across Os. A total of 50 trials per $-\Delta t$ value were run on each 0 .

A U-shaped masking function of $-\Delta t$ would be indicated if $-\Delta$ ts of 10 and $20 \mathrm{msec}$ yield more masking than $-\Delta t=0$. The amount of masking was taken as the percent of correctly identified letters at each $-\Delta t$ value.

\section{Results}

The graphs of the individual data show that, for Experiment 1, Os D.G. and G.K. gave U-shaped masking functions. Os D.G.P. and A.L.S. did not show evidence of U-shaped masking functions. Although two individual masking functions were U-shaped, there is no statistical support for the presence of U-shaped masking functions in Experiment 1 (see Fig.-1).

\section{EXPERIMENT 2}

The procedure and the $O s$ in Experiment 2 were the same as in Experiment 1, except that the four Os were run under conditions of target and mask luminance that differed from those used in Experiment 1. Two conditions were run, and one condition was completed before the other was run.

In Condition 1 the white portion of the target field was set at $40 \mathrm{fL}$ and the luminance of the mask field was set at $20 \mathrm{fL}$. In Condition 2 the target field luminance was $20 \mathrm{fL}$, while the mask field luminance was $10 \mathrm{fL}$. Thus, in both conditions of Experiment 2 the target possessed greater energy than the mask. This was done in an attempt to increase target recognition at $-\Delta t=0$ without increasing target recognition at $-\Delta t$ values greater than zero. It has been reported (Purcell, Stewart, \& Dember, 1969) that increasing target field luminance at $-\Delta t$ values greater than the target duration does not invariably increase target recognition. While it may not seem intuitive that increasing the target energy. relative to 

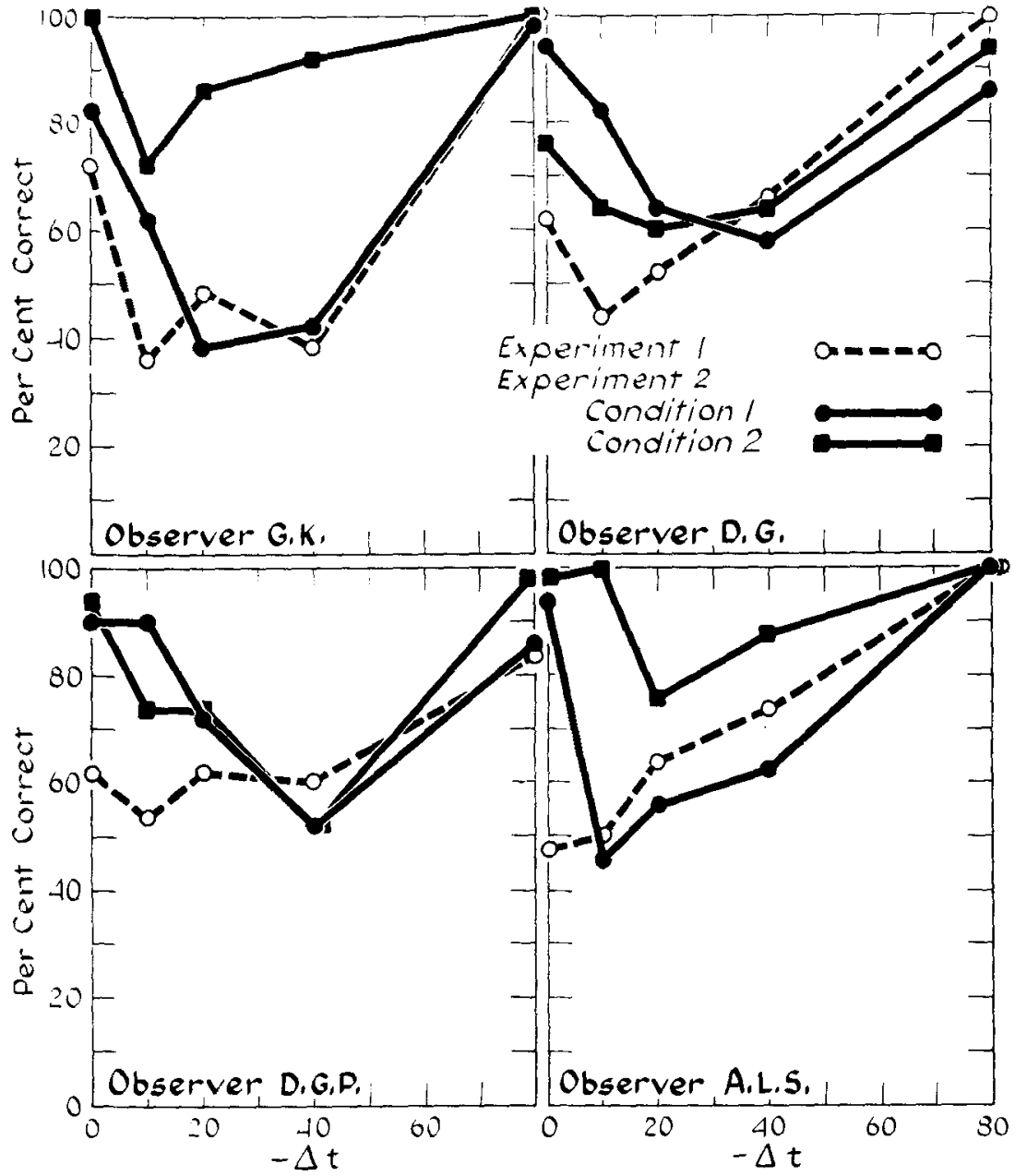

Fig. 1. Percent correct letter identification for Experiments 1 and 2.

mask energy, would still leave the target susceptible to masking at intermediate $-\Delta t$ values, the results of Purcell, Stewart, and Dember suggest just such a possibility.

As in Experiment 1, it was assumed at the outset that the presence of U-shaped masking functions would be indicated by more masking at $-\Delta t$ values of 10 and $20 \mathrm{msec}$ than at simultaneous presentation of target and mask fields. The $-\Delta t$ values of 40 and $80 \mathrm{msec}$ were nun, as in Experiment 1, to determine the range of possible U-shaped masking functions.

\section{Results}

The graphs of the individual data present evidence for U-shaped masking functions in both Conditions 1 and 2 of Experiment 2 . A repeated-measures analysis of variance on $-\Delta t$ values of 0,10 , and $20 \mathrm{msec}$ indicates that the increase in masking from 0 to $20 \mathrm{msec}$ is statistically reliable $[F(2,6)=46.39, \mathrm{p}<.001]$.

\section{EXPERIMENT 3}

Experiment 3 was designed to investigate the possibility of U-shaped masking functions using a homogeneous white field as a mask. Pilot testing showed that simultaneous presentation $(-\Delta t=0)$ of a 20-fL target and a 20-fL mask, both exposed for $20 \mathrm{msec}$, produced less masking than when the target and mask were presented at a $-\Delta t$ of $20 \mathrm{msec}$. Further increases in $-\Delta t$ above $20 \mathrm{msec}$ reduced the amount of masking.

As in Experiment 2, an increase in backward masking from a $-\Delta t$ of 0 to a $-\Delta t$ of $20 \mathrm{msec}$ indicates the presence of a U-shaped masking function. In order to verify the increase in masking, from a $-\Delta t$ of 0 to a $-\Delta t$ of $20 \mathrm{msec}$, two Os were run for 600 trials at $-\Delta t$ values equal to 0 and $20 \mathrm{msec}$. Trials were run in blocks of 50 , each block of $-\Delta t=0$ being paired with a block of $-\Delta t=20 \mathrm{msec}$. The $-\Delta t$ value presented first in each pairing was randomly determined; 12 pairs were run for each $O$. The target letter consisted of either a " $D$ " or an " $O$ " presented in a random sequence. The letters subtended approximately $24 \mathrm{~min}$ by $28.8 \mathrm{~min}$ of arc, with a strip width of $4.8 \mathrm{~min}$ of arc.

\section{Results}

O D.G.P. obtained a mean score of $74.50 \%$ correct letter identification at
$-\Delta t=0$ and a mean score of $60.66 \%$ correct at $-\Delta t=20 \mathrm{msec}$. A t test performed on the 12 pairs of 50 trials showed this difference to be statistically reliable $[t(11)=7.51, p<.001]$. O A.L.S. obtained a mean score of $80.50 \%$ correct letter identification at $-\Delta t=0$ and a mean score of $64.66 \%$ correct at $-\Delta t=20$ msec. Again a $t$ test showed this difference to be statistically reliable $[t(1)=5, p<.001]$. DISCUSSION

U-shaped masking functions have been documented only under conditions of metacontrast, and this fact has resulted in a tacit belief that such functions are impossible to produce using any other masking paradigm. The common practice of regarding metacontrast as a distinct form of visual masking has seemed plausible, for the most part, because these distinctive functions have not been found in other kinds of masking experiments. Contrary to these beliefs, Experiments 2 and 3 provide evidence for $U$-shaped masking functions of $-\Delta t$ using nonmetacontrast masking paradigms. Moreover, Experiment 2 is consistent with two unpublished reports of nonmetacontrast U-shaped masking functions, both of which are similar to Experiment 2 in that some contours in the masking field fall on retinal areas juxtaposed to those stimulated by the target's contours (Spencer \& Shuntich, 1970; Weisstein, 1970). While these results complicate any attempt to compile a list of functional differences which distinguish the various masking paradigms from each other, they do open the possibility of considering metacontrast as a special case of masking by an overlapping pattern mask. Certainly the results of Experiment 2 give prima facie evidence for this argument.

There are several studies in the masking literature that provide no evidence for U-shaped masking functions when a homogeneous masking field is used, as it was in Experiment 3 (Eriksen, 1966; Haber, 1968; Thompson, 1966). These studies have been interpreted by their authors to provide support for a simple luminance-summation contrast-reduction explanation of masking. Just as in Experiment 3, these studies used alphabetical characters as target stimuli, a homogeneous flash of light as the masking stimulus, and dark pre- and postexposure fields. Aside from these similarities, however, they differed from Experiment 3 in important ways. In two of the studies (Eriksen, 1966; Thompson, 1966), no masking data was reported for $-\Delta t=0$ and, therefore, neither can be compared directly to Experiment 3 . In our studies minimum masking was found at $-\Delta t=0$. It 
is possible that 4 -shaped masking functions manifest themselves over a limited range of

$\Delta t$ and that $-\Delta t=0$ must be tested to disclose them. Another difference is that in Experiment 3 the target was presented at exposure levels well above its absolute detection threshold: as in Experiment 2, the target exposure had sufficient luminance. duration, and contrast to be correctly identified about $80 \%$ of the time when target and mask were exposed at $-\Delta t=0$ and. as ascertained by pilot work, could be reported $100 \%$ of the time when exposed without a mask. On the other hand, Haber (1968) used a target exposure which allowed the target to be reported correctly only $80 \%$ of the time when presented without an accompanying masking flash and could be said to be near threshold. The effect of simultaneous exposure of target and mask fields is to reduce the physical contrast of stimuli in either field. It is likely that the reduction in the target's physical contrast resulted in the poor performance of Haber's Os at $-\Delta t=0$, while in Experiment 3 the target's contrast at simultaneous exposure was sufficient to permit good recognition scores.

A tentative conclusion is indicated by this analysis. If a target is readily masked at $-\Delta t=0$. by physical contrast reduction, it may be that whatever masking effects are operating at longer $-\Delta$ ts (say, $-20<\Delta \mathrm{t}<0$ ) will produce less profound effects. The end result will be an improvement in recognition at $-\Delta t$ values greater than zero when the target is difficult to recognize at simultaneous exposure, and a monotonic masking function will be manifest. It would seem, then, that a requirement for obtaining nonmonotonic, or U-shap2d, masking functions is that the target be above threshold in the absence of a mask and not be greatly susceptible to masking at $-\Delta \mathrm{t}=0$.

The requirement that the target be above threshold and also be partially resistent to masking at $-\Delta t=0$ in no way vitiates the assumptions of the luminance-summation model of masking. This model only stipulates that maximum masking is obtained at $-\Delta t=0$, without regard for the absolute level of masking obtained at $-\Delta t=0$. It may be that the limit beyond which luminance-summation explanations no longer hold can be defined by employing target exposures that are above threshold without a mask and only slightly susceptible to masking at $-\Delta t=0$.

\section{REFERENCES}

ERIKSEN, C. W. Temporal luminance summation effects in backward and forward masking. Perception \& Psychophysics, 1966, 1 , 87.92.

HABER, R. N. A replication and extension of the
Eriksen and Steffy (1964) experiment on short-term visual storage. Perception \& Psychophysics. 1968. 4, 341-343.

KAHNEMAN, D. Wethod, findings and theory in studies of visual masking. Psychological Bulletin, 1968, 70, 404-425.

PURCELL, D. G., STEWART, A. I., \& DEMBER, W. N. Backward masking: Facilitation through increased target-field luminance and duration. Psychonomic Science, $1969,15,87-88$.

RAAB, D. H. Backward masking. Psychological Bulletin, 1963, 60, 118-129.

SPENCER, T. J., \& SHUNTICH, R. Evidence for an interruption theory of backward masking. Paper presented at the meetings of the Midwestern Psychological Association, 1970.

THOMPSON, J. H. What happens to the stimulus in backward masking? Journal of Experimental Psychology, 1966, 71, 580-586.

WEISSTEIN, N. A Rashevsky-Landahl neural net: Simulation of metacontrast. Psychological Review, 1968, 75, 494-521.

WEISSTEIN, N. U-shaped and W-shaped masking functions obtained for monoptic and dichoptic disc-disc masking. Paper presented at the meetings of the Midwestern Psychological Association, 1970 .

\title{
Self-esteem and balance with impersonal attitude objects
}

\author{
W. PETER ARCHIBALD \\ University of Michigan, Ann Arbor, Mich. 48104
}

Previous research demonstrates that cognitive-consistency predictions should take Ss' self-esteem into account, for what is consistent for those with positive self-esteem may be inconsistent for those with negative self-esteem. In most studies the attitude object is the $\mathrm{S}$ himself, so that liking for others with whom one agrees is balancing for all Ss. For Ss with negative self-esteem, however, liking for others with whom one disagrees should be balancing when the object of disagreement is an impersonal one. In the present experiment $\mathrm{Ss}$ differing in selfesteem were presented with three levels of agreement-disagreement over the war in Vietnam, with three different hypothetical others. Contrary to the hypothesis, a Self-Esteem by Agreement interaction was not obtained, the only strong and consistent effect being a main effect for agreement. The results are discussed in terms of the limited range of the self-esteem variable and the questionable validity of the hypothesis.

The results of several experiments demonstrate that cognitive-consistency predictions should take Ss' self-esteem in to account, for what is consistent for those with positive selfesteem may be inconsistent for those with negative self-esteem. According to balance theory, for instance, the $S$ who dislikes himself should like others who dislike him and dislike others who like him (Deutsch \& Solomon, 1959; Jones \& Schneider, 1968; Wiest, 1965), although results have not always supported this contention (Dickoff, 1961; Jones, 1966; Walster, 1965).

When the attitude object is the $\mathrm{S}$ himself, as in the above example, liking others with whom one agrees and disliking others with whom one disagrees should 